\title{
Estrogenicity and Endocrine Disrupting Compounds in Istanbul Tap Water: A Case Study
}

\author{
Egemen Aydin, Badel Gun, M. Begum Tanis, Nilay Bilgin, Emel Topuz, Elif Pehlivanoglu-Mantas \\ Istanbul Technical University, Faculty of Civil Engineering, Environmental Engineering Department, Maslak, 34469, \\ Istanbul, Turkey \\ egemen.aydin@itu.edu.tr;badelgun@gmail.com; m.begumtanis@gmail.com; nilaybilgin@itu.edu.tr; topuze@itu.edu.tr; \\ pehlivano3@itu.edu.tr
}

\section{Extended Abstract}

Several natural and synthetic compounds in waters and wastewaters may affect the endocrine system of organisms due to their chemical structure. In this study, the presence of endocrine disrupting compounds (EDC) in tap water in Istanbul was investigated using a yeast-based estrogenicity bioassay (YES) [1] as well as measurement of concentration of bisphenolA (BPA) and bisphenol-S (BPS), which are selected as they have a high possibility of being present in drinking water among EDC. The samples were obtained from different households for all 5 different water treatment plants supplying water to Municipality of Istanbul, with the aim of providing comparative analyses of estrogenicity using results of bioassays and LCMS/MS analysis.

The concentration of EDC in treated water are generally in the low $\mathrm{ng} / \mathrm{L}$ range $[2,3]$. Similarly, the estrogenicity determined by bioassays in water is expected to have a low estradiol-(E2)-equivalent concentration [4, 5]. Therefore, a preconcentration step using solid phase extraction (SPE) is necessary prior to both analysis. Moreover, it is important to employ the same extraction steps to be able to evaluate and compare the results obtained using the bioassay and the chemical analyses. The first result of the study was the development of a SPE procedure that can be used for both the bioassay and the chemical analysis since the chemicals used for one procedure can interfere with the other procedure. For example, the use of $\mathrm{MeOH}$ as one of the eluents resulted in high recoveries for the bioassay, whereas it resulted in problems with peak resolution in LC-MS/MS. The optimized SPE included the use of a combination of ethanol and ethylacetate for conditioning and elution and DMSO as keeper. The SPE procedure allowed the concentration of analytes to $100 \mathrm{X}$ and 1000X for the bioassay and LC-MS/MS analyses, respectively.

For all 58 tap water samples, the estrogenicity was below the detection limit ( $2.7 \mathrm{ng} / \mathrm{L} \mathrm{E} 2$ equivalent), but some samples have BPA and BPS concentrations above the detection levels of $1 \mathrm{ng} / \mathrm{L}$ and $10 \mathrm{ng} / \mathrm{L}$, respectively. The highest BPA and BPS concentrations (18 ng/L and $60 \mathrm{ng} / \mathrm{L}$, respectively) were detected in the tap waters of households obtaining their water from the same water treatment plant (WTP). The source water for the WTP is a lake close to the sea and due to the seawater intrusion containing bromide, this WTP employs only chlorination as the disinfection method instead of ozonation followed by post-chlorination used in all the other treatment plants. Considering the differences in disinfection processes, one can conclude that ozonation may provide useful for the removal of EDC that might exist in raw water. The results also indicate that the seasons and the amount of precipitation has an effect on the concentration of EDC in tap water samples. The concentration of both BPA and BPS were below the detection limit in all samples obtained in winter and spring seasons which corresponds to rainy seasons.

Considering that a concentration of $24 \mu \mathrm{g} / \mathrm{lBPA}$ in drinking water poses only a threat based on its estrogenicity upon the consumption of $124 \mathrm{~L}$ per day [6], it can be concluded that the tap water in Istanbul does not pose a serious threat due to the estrogenicity.

\section{Acknowledgement}

This work is supported by TUBITAK (Project \#112Y321) and ITU Scientific Research Projects (Project\#38813 and Project\#37165). 


\section{References}

[1] E. J. Routledge and J. P. Sumpter, "Estrogenic activity of surfactants and some of their degradation products assessed using a recombinant yeast screen," Environ. Toxicol. Chem., vol. 15, no. 3, pp. 241-248, 1996.

[2] S. Maggioni, P. Balaguer, C. Chiozzotto, and E. Benfenati, "Screening of endocrine-disrupting phenols, herbicides, steroid estrogens, and estrogenicity in drinking water from the waterworks of 35 Italian cities and from PET-bottled mineral water," Environ. Sci. Pollut. R., vol. 20, no. 3, pp. 1649-1660, 2013

[3] H. C. Zhang, T. Xu , X. L. Hu, W. H. Pang, and D. Q. Yin, "The distributions, removals and estrogenic effects of selected endocrine disrupting chemicals in two drinking water factories in China," J. Water Health, vol. 11, no. 1, pp. 41-50, 2013.

[4] A. Krein, J. Y. Pailler, C. Guignard, A. C. Gutleb, L. Hoffmann, B. Meyer, S. Keßler, P. Berckmans, and H. E. Witters, "Determination of Estrogen Activity in River Waters and Wastewater in Luxembourg by Chemical Analysis and the Yeast Estrogen Screen Assay," Environment Pollut., vol. 1, no. 2, pp. 86-96, 2012.

[5] M. Wagner and J. Oehlmann, "Endocrine disruptors in bottled mineral water: estrogenic activity in the E-Screen," $J$. Steroid Biochem., vol. 127, no. 1-2, pp. 128-135. 2011.

[6] A. Guart, F. Bono-Blay, A. Borrell, and S. Lacorte, "Effect of bottling and storage on the migration of plastic constituents in Spanish bottled waters," Food Chem., vol. 156, pp. 73-80. 2014. 